\section{Pulmonary hyper- tension and pregnancy: a series of eight cases}

Kari G. Smedstad MB FRCPC, Robert Cramb MD FRCPC, David H. Morison MB FRCPC
This is the report of a series of eight patients with pulmonary hypertension (primary and secondary) who delivered at the McMaster University Medical Centre between 1978 and 1987. Seven of the eight patients delivered vaginally and had a successful outcome. The eighth patient was admitted as an emergency and died shortly after Caesarean section under general anaesthesia, performed to save the infant. The other seven patients were all managed by a team, including anaesthetists, cardiologists and obstetricians, from about $25 w k$. The patients were hospitalized pre-partum and received oxygen therapy and anticoagulation with heparin. Analgesia in labour was managed, once anticoagulation was reversed, by low concentrations of epidural bupivacaine $(0.125 \%-0.375 \%)$ and fentanyl. The patients were monitored during labour and delivery with oximetry and arterial and central venous pressure lines. Pulmonary arterial lines were not used because of increased risk and questionable usefulness. Vaginal delivery was managed with vacuum extraction or forceps lift-out to minimize the stress of pushing. After delivery, all patients were monitored in an intensive care unit for several days, anticoagulation was restarted, and all patients were discharged home taking oral anticoagulant therapy. The successful management of pulmonary hypertension in pregnancy should include team management started early in pregnancy and controlled vaginal delivery utilizing epidural analgesia.

Ce travail porte sur une série de huit patientes souffrant dhypertension pulmonaire (primaire et secondaire) qui ont accouché au centre médical de l'université McMaster de 1978 à 1987. Sept des huit patientes ont donné naissance par voie vaginale avec succès. La huitième a été admise en urgence et est décédée peu de temps après une césarienne sous anesthésie générale réalisée dans le but de sauver le foetus. Les sept

\section{Key words}

ANAESTHESIA: obstetric; LUNG: pulmonary hypertension.

From the Department of Anaesthesia, McMaster University, 1200 Main Street West, Hamilton, Ontario L8N $3 Z 5$.

Address correspondence to: Dr. Kari G. Smedstad.

Accepted for publication 6th February, 1994. autres ont été suivies à partir de la 25 semaine par une équipe qui comprenait des anesthésistes, des cardiologues et des obstétriciens. Elles ont été hospitalisées avant l'accouchement et ont reçu de l'oxygénothérapie et de l'héparine. Pendant le travail, une fois l'anticoagulation renversée, l'analgésie a été produite par de la bupivacaine 0,125\%-0,375\% et du fentanyl. Pendant le travail et l'accouchement, les patientes ont été monitorées par oxymétrie, tension veineuse centrale et pression artérielle sanglante. On n'a pas installé de cathéter artériel pulmonaire à cause du risque accru de complications et de son utilité douteuse. L'extraction vaginale a été réalisé par application de ventouse ou de forceps pour diminuer le stress de la poussée abdominale. Après l'accouchement, toutes les patientes ont été monitorées à l'unité de soins intensifs pendant plusieurs jours et anticoagulées de nouveau. Elles ont reçu leur congé de l'hôpital avec anticoagulothérapie. La gestion de lhypertension pulmonaire de la femme enceinte doit être multidisciplinaire et l'accouchement doit s'effectuer sous contrôle, avec une anesthésie épidurale.

Successful management of pregnancy, labour and delivery in women with pulmonary hypertension is a difficult challenge to the whole health care team. The anaesthetist can play a vital part in securing a successful outcome. Pulmonary hypertension and pregnancy is regarded as a lethal combination and death may occur regardless of the severity of the disease. We contend that the favourable outcome in our cases is associated with the multidisciplinary team approach to critical care obstetrics.

Pulmonary hypertension exists when the mean pulmonary artery pressure (PAP) exceeds $25 \mathrm{mmHg}$. Primary pulmonary hypertension (PPH) is a disease of the pulmonary vessels leading to hypertrophy and failure of the right ventricle. Eisenmenger's syndrome is defined as pulmonary hypertension and a right to left, or bidirectional, shunt with peripheral cyanosis. The increase in PAP is secondary to an intracardiac shunt from a congenital lesion. Secondary pulmonary hypertension may also develop in long-standing mitral valve disease due to increase in left atrial pressure and volume, and increase in pulmonary venous pressures. Pulmonary arterial wall thickening and fibrosis results and the elevated PAP becomes permanent. The normal cardiovascular changes of 
TABLE I Cardiac status

\begin{tabular}{|c|c|c|c|c|c|c|c|c|}
\hline $\begin{array}{l}\text { Case } \\
y r\end{array}$ & Diagnosis & $\begin{array}{l}\text { Age } \\
y r\end{array}$ & Parity & Catheter findings & $2 D$ Echo & $\begin{array}{l}\mathrm{SpO}_{2} \\
\mathrm{mmHg}\end{array}$ & $\begin{array}{l}H b \\
g \cdot L^{-1}\end{array}$ & $\begin{array}{l}H C T \\
\%\end{array}$ \\
\hline$\# 1$ & VSD & & & $\begin{array}{l}\text { (1975) PAP 124/64 } \overline{90} \\
\text { R:L shunt } 5.1 \text { I }\end{array}$ & & 78 & & \\
\hline 1978 & Eisenmenger & 23 & Gl & PVR 15.2 Wood u & & $89\left(\mathrm{O}_{2}\right)$ & 151 & 44 \\
\hline$\# 2$ & PDA & & & (1972)PAP 108/71 $\overline{85}$ & $\begin{array}{l}\text { (1982) RVH }(4.1 \mathrm{~cm}) \\
\text { PH }\end{array}$ & 85 & & \\
\hline 1982 & Eisenmenger & 24 & G1 & R:L 2:1 shunt & Abn septal motion & $93\left(\mathrm{O}_{2}\right)$ & 140 & 40 \\
\hline $\begin{array}{l}\# 3 \\
1983\end{array}$ & $\begin{array}{l}\text { ASD } \\
\text { Eisenmenger }\end{array}$ & 30 & $\mathrm{G} 2 \mathrm{P} 1$ & $\begin{array}{l}\text { (1983) PAP 100/45 } . \overline{65} \\
\text { post-delivery }\end{array}$ & $\begin{array}{l}\text { RVH }(4.9 \mathrm{~cm}) \\
\text { PH } \\
\text { R:L shunt }\end{array}$ & & 109 & 33 \\
\hline$\# 5$ & Same & & & & & 91 & & \\
\hline 1984 & Patient & 31 & G3P2 & Same patient & Same patient & $97\left(\mathrm{O}_{2}\right)$ & 126 & 40 \\
\hline $\begin{array}{l}\not 4 \\
1983\end{array}$ & $\begin{array}{l}\text { VSD } \\
\text { Eisenmenger }\end{array}$ & 24 & $\mathrm{G} 2 \mathrm{Al}$ & & $\begin{array}{l}\text { RVH }(3.1 \mathrm{~cm}) \\
\text { PH }\end{array}$ & $\begin{array}{l}85 \\
90\left(\mathrm{O}_{2}\right)\end{array}$ & 150 & 44 \\
\hline $\begin{array}{l}\# 6 \\
1986\end{array}$ & $\begin{array}{l}\text { Chronic } \\
\text { Pulmonary } \\
\text { Thromboembolism }\end{array}$ & 33 & G4P3 & $\begin{array}{l}\text { PAP } 65 / 34 . \overline{44} \\
\text { PAWP 23.31 }\end{array}$ & & $\begin{array}{l}78 \\
85\left(\mathrm{O}_{2}\right)\end{array}$ & 130 & 37 \\
\hline $\begin{array}{l}\# 7 \\
1987\end{array}$ & $\begin{array}{l}\text { Primary } \\
\text { Pulmonary } \\
\text { Hypertension }\end{array}$ & 30 & G3P1AI & $\begin{array}{l}\text { PAP } 70 / 30 . \overline{43} \\
\text { post-delivery }\end{array}$ & $\begin{array}{l}\text { RVH }(4.4 \mathrm{~cm}) \\
\text { TR }\left(4.2 \mathrm{~m} \cdot \mathrm{sec}^{-1}\right) \text { PH } \\
\text { PAP } 70 \text { (Doppler) }\end{array}$ & $\begin{array}{l}97 \\
99\left(\mathrm{O}_{2}\right)\end{array}$ & 136 & 40 \\
\hline $\begin{array}{l}\# 8 \\
1987\end{array}$ & $\begin{array}{l}\text { Pulmonary } \\
\text { Hypertension } \\
\text { Mitral Disease }\end{array}$ & 31 & G2P1 & & $\begin{array}{l}\text { LAH }(6 \mathrm{~cm}) \\
\text { PAP } 75-80 \\
\text { PAP } 60 \text { on } \mathrm{O}_{2}\end{array}$ & $\begin{array}{l}82-92 \\
95\left(\mathrm{O}_{2}\right)\end{array}$ & 106 & 32 \\
\hline
\end{tabular}

m: mean; PAP: pulmonary artery pressure; R:L: right to left; PVR: pulmonary vascular resistance; Wood u: $n=1-2 ;$ RVH: right ventricular hypertrophy; PH: pulmonary hypertension; TR: tricuspid regurgitation; LAH: left atrial hypertrophy; PAWP: pulmonary wedge pressure; G: gravida; P: para; A: abortus; VSD: ventricular septal defect; PDA: patent ductus arteriosus; ASD: atrial septal defect; all pressures measured in mmHg; HB: haemoglobin; HCT: haematocrit.

pregnancy, labour, and delivery, will place an excessive burden on the cardiovascular system in those patients who already have marginal cardiac function before pregnancy. Increases of $35-45 \%$ in blood and plasma volume may precipitate right ventricular failure. In cardiac disease states the normal $15 \%$ decrease in total peripheral resistance may not be sufficient to compensate for the volume increase. If the right ventricle fails in the presence of pulmonary hypertension, left ventricular filling will decrease and low output failure and sudden death may occur. The critical lesion in Eisenmenger's syndrome is pulmonary arteriolar hypertrophy. If the pulmonary vascular resistance changes suddenly, the presence of a shunt may protect the right ventricle to some extent from sudden increases in PAP. In patients with PPH this protective mechanism does not exist, which may explain their higher mortality in pregnancy.

The mortality rate of patients with Eisenmenger's syndrome who carry a pregnancy to viability is reported at $27-30 \%$, and at $7 \%$ for a therapeutic abortion. ${ }^{1,2}$ If pregnancy-induced hypertension develops, the mortality increases to $66 \% .^{1,2}$ Caesarean section carries a maternal mortality rate of $46-70 \%$ in Eisenmenger's syndrome. ${ }^{3}$ The fetal and perinatal mortality associated with pulmonary hypertensive mothers is approximately $30 \%$ and only $25 \%$ of pregnancies reach term. One-third of infants born suffer intrauterine growth restriction. ${ }^{1}$ The maternal mortality in young women with primary pulmonary hypertension who deliver vaginally is $50-60 \% .^{2,4}$

Fortunately, such cases are rare. Eisenmenger's syndrome is present in approximately $3 \%$ of patients with congenital heart disease, and they are counselled to avoid pregnancy. Primary pulmonary hypertension is a rare disease which particularly affects young women and may be associated with pregnancy per se. ${ }^{5}$ In our high-risk obstetric unit, which serves as a referral centre for a population of approximately one million, we have managed seven cases of secondary and one case of primary pulmonary hypertension to term over a 15 -yr period. This report details these cases, of which seven were managed with vaginal delivery and survived. One patient in our series delivered twice. One patient, previously undiagnosed, who presented in extremis and underwent Caesarean section, died. 
TABLE II Patient management

\begin{tabular}{|c|c|c|c|c|c|c|c|c|}
\hline \multirow{2}{*}{$\begin{array}{l}\text { Case } \\
y r\end{array}$} & \multirow{2}{*}{$\begin{array}{l}\text { Admit } \\
w k\end{array}$} & \multicolumn{2}{|c|}{ Anti-coagulation } & \multirow{2}{*}{$\begin{array}{l}\text { Anaesthesia } \\
\text { analgesia }\end{array}$} & \multirow{2}{*}{$\begin{array}{l}\text { Blood } \\
\text { loss }\end{array}$} & \multirow{2}{*}{$\begin{array}{l}\dot{N} \\
\text { fluids }\end{array}$} & \multirow[b]{2}{*}{ Oxytacin } & \multirow[b]{2}{*}{ Outcome and comment } \\
\hline & & Pre-delivery & Post-delivery & & & & & \\
\hline $\begin{array}{l}\# 1 \\
1978\end{array}$ & 25 & iv 20,000 & iv 20,000 & $\begin{array}{l}\text { Epidural } \\
\text { bupivacaine } 0.375 \% \\
26 \mathrm{ml} / 9 \mathrm{hr}\end{array}$ & $550 \mathrm{ml}$ & $\begin{array}{l}2 \mathrm{u} \text { blood } \\
500\end{array}$ & $\begin{array}{l}50 \mathrm{iu} \\
\text { in } 500 \mathrm{ml}\end{array}$ & $\begin{array}{l}\text { Home day } 21 \\
\text { Coumadin } 6 \text { mo } \\
\text { ITP }\end{array}$ \\
\hline$\# 2$ & & & & $\begin{array}{l}\text { Epidural } \\
\text { bupivacaine } 0.25 \%\end{array}$ & & & $20 \mathrm{iu}$ & Home day 12 \\
\hline 1982 & 36 & $s c 10,000$ & sc 30,000 & $30 \mathrm{ml} / 7 \mathrm{hr}$ & $<500 \mathrm{ml}$ & 750 & in $500 \mathrm{ml}$ & Coumadin 6 mo \\
\hline $\begin{array}{l}\# 3 \\
1983\end{array}$ & 39 & & iv $20-30,000$ & $\begin{array}{l}\text { Epidural } \\
\text { bupivacaine } 0.375 \% \\
13 \mathrm{ml} / 3 \mathrm{hr}\end{array}$ & $<500 \mathrm{ml}$ & 1500 & $\begin{array}{l}50 \mathrm{iu} \\
\text { in } 1000 \mathrm{ml}\end{array}$ & $\begin{array}{l}\text { D\&C day } 5 \& 15 \text { (endometritis) } \\
\text { heart failure day } 6 \text {, DVT day } 7 \\
\text { Home day } 25 \text {, Coumadin } 6 \text { mo }\end{array}$ \\
\hline $\begin{array}{l}\# 5 \\
1984\end{array}$ & 30 & sc 10,000 & (u) 15-20000 & $\begin{array}{l}\text { Epidural } \\
\text { bupivacaine } 0.25 \%\end{array}$ & $1 \mathrm{~mm} \mathrm{ml}$ & 600 & & $\begin{array}{l}\text { Home day } 9 \\
\text { Coumadin } 3 \text { mo }\end{array}$ \\
\hline$\# 4$ & & & & $\begin{array}{l}\text { Epidural } \\
\text { bupivacaine } 0.25 \%\end{array}$ & & & & $\begin{array}{l}\text { Home day } 15 \text {, angina } \\
\text { Coumadin } 6 \text { mo }\end{array}$ \\
\hline 1983 & 30 & $\dot{\sim} 20,000$ & $i v 20,000$ & $\begin{array}{l}15 \mathrm{ml} / 2 \mathrm{hr} \\
\mathrm{C} / \text { section } \mathrm{GA}\end{array}$ & $400 \mathrm{ml}$ & 1000 & & $\begin{array}{l}2 \text { yr follow-up } \\
\text { died } 12 \text { hr post-partum } \\
\text { post-mortem: chronic pulmonary }\end{array}$ \\
\hline $\begin{array}{l}\# 6 \\
1986\end{array}$ & 34 & $\dot{i}$ full dose & & $\begin{array}{l}\mathrm{STP} / \text { fentanyl/pancuronium } \\
\mathrm{O}_{2} / \text { halothane } 0.5 \%\end{array}$ & $500 \mathrm{ml}$ & 1000 & $\begin{array}{l}50 \mathrm{iu} \\
\text { in } 1000 \mathrm{ml}\end{array}$ & $\begin{array}{l}\text { thromboembolism, PH } \\
\text { patent foramen ovale }\end{array}$ \\
\hline $\begin{array}{l}\# 7 \\
1987\end{array}$ & 26 & $\dot{N} 15-20,000$ & iv sc $15-20,000$ & $\begin{array}{l}\text { Epidural infusion } \\
\text { bupivacaine } 0.125 \% \\
18 \mathrm{ml} / 3 \mathrm{hr} \\
\text { fentanyl } 50 \mu \mathrm{g}\end{array}$ & $<500 \mathrm{ml}$ & 500 & & $\begin{array}{l}\text { Home day } 28 \\
\text { Coumadin } \\
\text { heart-lung transplant } 18 \text { mo } \\
\text { well } 3 \text { yr post-delivery }\end{array}$ \\
\hline $\begin{array}{l}\$ 8 \\
1987\end{array}$ & 32 & sc $10-15,000$ & iv se $15-2000$ & $\begin{array}{l}\text { Epidural infusion } \\
\text { bupivacaine } 0.125 \% \\
30 \mathrm{ml} / 3 \mathrm{hr}\end{array}$ & $400 \mathrm{ml}$ & 250 & 5 iu im & $\begin{array}{l}\text { Home day } 10 \\
\text { Coumadin } 3 \text { mo } \\
\text { digoxin furosemide } \\
\text { mitral valve replacement } 4 \mathrm{yr}\end{array}$ \\
\hline
\end{tabular}

Anti-coagulation expressed as Heparin, international units; sc: subcutaneous; iv: intravenous; DVT: deep vein thrombosis; ITP: immune thrombocytopenic purpura; GA: general anaesthesia; STP: sodium thiopentone; $i v$ fluids: crystalloid solutions of normal saline or Lactated Ringers; im Intramuscular.

\section{Case histories (see Table I, II and III for details)}

Case \#I - VSD - Eisenmenger's (1978)

A 23-yr-old primipara with a large ventricular septal defect (VSD), marked pulmonary hypertension, cyanosis and intrauterine growth retardation, was admitted in the 25 th wk of pregnancy. She remained in hospital receiving oxygen therapy by nasal prongs and received heparin 20,000 iu daily iv until labour was induced at $38 \mathrm{wk}$ using oxytocin $1-14 \mathrm{mU} \cdot \mathrm{min}^{-1}$. Monitoring during labour included ear oximetry, electrocardiogram (ECG), radial arterial line, and a central venous (CVP) line for pressure measurements and venous access. Intravenous protamine $50 \mathrm{mg}$ was given to reverse the heparin effect. Then, a lumbar epidural catheter was inserted for pain relief as soon as contractions became uncomfortable at
$2 \mathrm{~cm}$ cervical dilatation. The epidural block was established slowly with intermittent doses of 2-4 ml bupivacaine $0.375 \%$. The $\mathrm{SpO}_{2}$ remained at $89-90 \%$ during labour and the blood pressure remained stable. This patient received a blood transfusion post partum, as was then usual practice. After delivery, the patient was monitored in the Intensive Care Unit (ICU) and anticoagulation therapy using heparin was restarted. She went home three weeks later. Coumadin therapy continued for several months.

Case \#2 - PDA - Eisenmenger's (1982)

This patient was a 24 yr-old gravida 1 with patent ductus arteriosus (PDA) documented since age two. She had a past history of hyperthyroidism treated medically and was receiving thyroid replacement therapy. She developed 
TABLE III Labour and delivery

\begin{tabular}{lllll}
\hline Case & $W k$-labour & Delivery & Baby $g$ & Apgar \\
\hline 1 & 38 induced & forceps & 2270 & $10-10$ \\
2 & 40 spont & forceps & 2940 & $9-10$ \\
3 & 39 spont & forceps & 3190 & $9-10$ \\
5 & 39 spont & forceps & 4130 & $8-9$ \\
4 & 35 spont & forceps & 2050 & $8-9$ \\
6 & 34 & C/S & 2010 & $5-9$ \\
7 & 34 induced & vacuum & 1650 & $9-10$ \\
8 & 36 spont & vacuum & 2670 & $8-9$ \\
\hline
\end{tabular}

Spont: spontaneous onset of labour; forceps: outlet forceps lift out; vacuum: outlet vacuum extraction.

thrombocytopenia. She was admitted at $36 \mathrm{wk}$ because of increasing weight gain, oedema and shortness of breath. On clinical examination, the patient was cyanosed with signs of right ventricular hypertrophy and pulmonary hypertension. She was treated with 10,000 iu heparin $s c$ daily for two weeks before delivery. The platelet count remained around 90,000 . The internists assumed a link between the purpura and her previous hyperthyroidism. When she went into spontaneous labour, her clotting factors were normal. An arterial line, ECG and ear oximetry were used for monitoring. During labour, $\mathrm{SpO}_{2}$ remained at $89-93 \%$ with a blood pressure at $100-115$ systolic and a heart rate of 95-115 bpm. The epidural catheter was inserted early in labour and incremental doses of 2-4 $\mathrm{ml}$ bupivacaine $0.25 \%$ were given till the block was established. Fifteen minutes after delivery, the systolic blood pressure decreased to $75 \mathrm{mmHg}$ with tachycardia and a decrease in $\mathrm{SpO}_{2}$ to 78-85\%, accompanied by vomiting. The patient was treated with a bolus infusion of $500 \mathrm{ml}$ lactated Ringer's solution. Over the next week, several hypotensive episodes in the ICU were treated with vasopressors and fluids. She was discharged home on the 12th day in good condition and was doing well at followup six months later.

\section{Case \#3 - ASD - Eisenmenger's (1983) and \\ Case \#5 - ASD - Eisenmenger's (1984)}

This 30-yr-old patient was admitted in labour under the care of the family physician at 39 wk. She gave birth to a healthy baby after ten hours of labour. Epidural analgesia with bupivacaine $0.375 \%$ in $3-6 \mathrm{ml}$ increments provided pain relief. No diagnosis of cardiac disease had been made before this delivery. Five days post partum, she started bleeding and underwent a dilatation and $\mathrm{cu}-$ rettage ( $D$ and $C$ ) for retained placental products. The next day, she developed cyanosis and heart failure. A cardiologist examined her, and echocardiography (2D Echo) revealed a large atrial septal defect (ASD) with right to left shunt and marked right ventricular hypertrophy. She was treated for endometritis and required a further $\mathrm{D}$ and $\mathrm{C}$ two weeks later. She then developed a pelvic vein thrombosis and received heparin 20,000 iu daily $i v$. She went home four weeks after delivery receiving coumadin therapy. Post-partum cardiac investigations as shown in Table I. Despite contraceptive counselling, she presented again 14 mo later at 25 wk gestation. This time her obstetrician admitted her to hospital at $30 \mathrm{wk}$ gestation for observation, heparinization, and oxygen therapy. Now there was evidence of pulmonary and tricuspid regurgitation. Labour started spontaneously at 39 wk. An arterial line and a CVP line were inserted under intravenous sedation with increments of meperidine to $20 \mathrm{mg}$. After $50 \mathrm{mg}$ protamine $i v$ and with normal coagulation factors, an epidural catheter was inserted and $3 \mathrm{ml}$ increments of bupivacaine $0.25 \%$ were given until the patient was comfortable. Ear oximetry showed an $\mathrm{SpO}_{2}$ of 95-96\% and the CVP measured 5-10 $\mathrm{cm} \mathrm{H}_{2} \mathrm{O}$ throughout labour, with a brief decrease of $\mathrm{SpO}_{2}$ to $88 \%$ and the CVP to $4 \mathrm{~cm}$ after delivery. She was monitored in the ICU and Coronary Care Unit (CCU) for six days and discharged home two weeks post partum.

\section{Case \#4 - VSD - Eisenmenger's (1983)}

This 24-yr-old primiparous patient's VSD was first diagnosed at age 12, when she already had established Eisenmenger's syndrome. Since age 14, she had suffered from chest pain, intermittent haemoptysis and dyspnoea, and was cyanotic with exercise. At age 20 , she underwent a therapeutic abortion at eight weeks gestation. The present pregnancy was planned, despite medical advice. She presented at six weeks with transient cerebral ischaemic attacks. Throughout the pregnancy she was treated with acetylsalicylic acid and dipyridamole. At 30 wk she was admitted for continuous oxygen therapy, heparinization and rest for the remainder of the pregnancy. She was cyanotic with severe finger clubbing. $\mathrm{Her} \mathrm{SpO}_{2}$ increased from $80 \%$ to $88 \%$ during continuous oxygen therapy. The baby showed intrauterine growth restriction. She had frequent episodes of severe protracted chest pain needing injections of nalbuphine $10 \mathrm{mg}$. She went into spontaneous labour at 35 wk. After reversal of heparinization, with protamine sulphate, an arterial line and CVP line were inserted. When the cervix was $4 \mathrm{~cm}$ dilated, an epidural catheter was introduced and intermittent doses of $3 \mathrm{ml}$ bupivacaine $0.25 \%$ given. Throughout labour, the systemic blood pressure remained stable in the 100-115/50 $\mathrm{mmHg}$ range, the mean CVP varied from 10-12 mmHg, and $\mathrm{SpO}_{2}$ remained at $85-88 \%$ on $\mathrm{O}_{2}$. She had frequent episodes of chest pain thought to be angina pectoris, and was nursed in the CCU for three 
weeks. There were numerous episodes of desaturation, down to a $\mathrm{SpO}_{2}$ of $68 \%$ by ear oximetry over the first week, but her condition then stabilized. She was discharged home in good condition and a two year followup was satisfactory.

\section{Case \#6 - Undiagnosed until postmortem (1986)}

This 33-yr-old patient had three previous uneventful pregnancies. She was seen in another hospital three months before admission because of an increase in heart rate. Mitral valve prolapse and mitral valve dysfunction showed on 2D Echo. At 34 wk gestation, she was admitted to a Level II hospital with progressive dyspnea for 6-8 wk. Ventilation/perfusion scans were equivocal. The ECG showed an incomplete right bundle branch block. The chest $x$-ray showed a dilated pulmonary artery segment. Her physicians made a presumptive diagnosis of pulmonary embolization and started heparin therapy. She was transferred to our centre, as an emergency. Her respiratory status deteriorated markedly in the ICU over the first $12 \mathrm{hr}$ and it was decided to deliver her by Caesarean section to save the infant. Arterial and Swan Ganz catheters were inserted prior to induction of anaesthesia. The anaesthetist on call elected to use a general anaesthetic with thiopentone $200 \mathrm{mg}$, succinylcholine $100 \mathrm{mg}$ and fentanyl $100 \mu \mathrm{g}$ because of her coagulation status. Anaesthesia was maintained with halothane $0-0.5 \%$ and $\mathrm{N}_{2} \mathrm{O} / \mathrm{O}_{2}$, in a $50 / 50$ mixture. Arterial blood gases, ten minutes postinduction, showed $\mathrm{PO}_{2}$ of $65, \mathrm{PCO}_{2}$ of 23 , $\mathrm{pH}$ of 7.41 and bicarbonate 15.5. The mother became progressively hypotensive following the delivery of the infant and was transferred to the ICU, with an endotracheal tube in place and continued to receive positive-pressure ventilation. Twelve hours later, she suddenly developed cyanosis and tachycardia, followed by electromechanical dissociation and death. Post-mortem showed patent pulmonary vessels of a normal size and no evidence of pulmonary emboli on gross examination. The pulmonary artery showed signs of increased pressure. There was a mildly dilated right atrium and borderline hypertrophy of the right ventricle. There was a patent foramen ovale and the mitral valve was normal. Histopathological examination "found evidence of chronic pulmonary thromboembolism that appeared to have occurred at some remote time in the past." There was no evidence of recent pulmonary thromboembolism or amniotic fluid embolism.

\section{Case \#7 Primary pulmonary hypertension (1987)}

This woman was a 30 -yr-old para 1 gravida 3 . Her first baby was delivered by Caesarean section for "cephalopelvic disproportion" (CPD). She saw her doctor at 19 wk gestation with a five-week history of cough, fatigue and palpitations. She gained $5 \mathrm{~kg}$ in weight in two weeks and had four pillow orthopnoea and chest pain. A ventilation-perfusion scan was noncontributory. Cardiac findings which established the diagnosis of PPH of pregnancy as shown in Table I. She was admitted at 26 wk gestation for continuous oxygen therapy and intravenous heparin, 20,000 iu daily. Labour was induced at $34 \mathrm{wk}$ using a prostaglandin $E_{2} 0.5 \mathrm{mg}$ gel insert because of her history of a Caesarean section for CPD. An arterial line was inserted and protamine sulphate $50 \mathrm{mg} i v$ was given over $15 \mathrm{~min}$, then a jugular CVP line and an epidural catheter were positioned. Four hours after prostaglandin application epidural analgesia commenced using fentanyl $50 \mu \mathrm{g}$ and increments of $3 \mathrm{ml}$ bupivacaine $0.125 \%$ followed by a continuous epidural infusion. Following the delivery, the patient was nursed in the CCU and given full heparin therapy. The first $48 \mathrm{hr}$ were uneventful. She then had a stormy course for three weeks with repeated episodes of hypotension and right-sided volume overload. It was necessary to put in a pulmonary artery catheter one week post partum to monitor cardiovascular responses to therapeutic agents. She was treated with dopamine and furosemide, and later nitroglycerine infusions, as well as calcium channel blockers. Amrinone was tried. The response to nitrates and calcium channel blockers was disappointing. These drugs were discontinued when they precipitated severe hypotension. The patient's condition stabilized on dobutamine and furosemide. She was discharged home four weeks after delivery taking furosemide alone. Eighteen months later she underwent a successful heart-lung transplant.

\section{Case $\# 8$ - Pulmonary hypertension $2^{\circ}$ to mitral valve disease (1987)}

This patient had childhood rheumatic fever and mitral valve disease. Five years before this pregnancy, she underwent a mitral commissurotomy. At that time, she already had a 2-yr-old child. In this pregnancy she was hospitalized at $28 \mathrm{wk}$ with severe tricuspid regurgitation, moderate mitral stenosis, severe mitral regurgitation, and pulmonary hypertension. The chest $x$-ray showed virtually no vessels in the lower lung fields with marked vascular redistribution to the upper zones. Oxygen therapy, rest and digitilization improved her symptoms and she went home on this regimen. She was readmitted at 32 wk and stayed till ten days after delivery. Spontaneous labour started at $36 \mathrm{wk}$. She had a lumbar epidural catheter inserted before she became uncomfortable, and the first dose of drug was given when the contractions became stronger. An internal jugular CVP line and an arterial line were inserted for monitoring. Bupivacaine $0.125 \%$ in $3 \mathrm{ml}$ aliquots to $12 \mathrm{ml}$ over one hour was given epidurally followed by $18 \mathrm{ml}$ by infusion over the next two 
hours. Her cardiovascular status was stable throughout the delivery. Post partum she was treated for congestive heart failure and chest pain. She was anticoagulated with heparin, which was changed to coumadin on discharge. Six months post partum she was readmitted for an uneventful laparoscopic tubal ligation. Four years later she underwent a mitral valve replacement.

\section{Case management}

All the survivors presented to our hospital early in pregnancy. Six of these seven patients were known to have pulmonary hypertension before the pregnancy. Existing cardiac catheter findings, or 2D Echo and Doppler studies, confirmed the diagnosis and the severity of the disease.

When a patient with pulmonary hyptertension presented to the Antenatal Clinic, the whole management team was notified. The team consisted of specialists in cardiology, haematology, neonatology, nursing, obstetrics and obstetric anaesthesia. In one case, the Hospital Ethics Committee was involved, because the patient wanted the baby's survival to take precedence over her own. Frequent consultations and patient contact were established early. The obstetrical anaesthetists explained the anaesthetic considerations and management plans when first consulted, and visited the patients regularly before delivery. The rapport and trust which developed between the anaesthetists and the patient before delivery was instrumental in relieving anxiety and fear at the time of birth. The patient, her family and all the team members understood the rationale for the anaesthetic management for labour.

All our survivors were admitted to hospital for 4-8 wk before delivery. They received oxygen therapy using nasal prongs at $2-4 \mathrm{~L} \cdot \mathrm{min}^{-1}$ for several hours every day and while sleeping. Percutaneous oxygen saturation using a Hewlett Packard ear oximeter was monitored daily. Haematocrit determinations were frequent. The patients received anticoagulation therapy for prevention of pulmonary emboli. The haematologists monitored the patient's coagulation factors and used heparin to keep the prothrombin time within appropriate limits. The therapy varied in that some patients required $i v$ heparin in doses up to 20,000 iu daily, and others received $s c$ heparin (5000-10,000 iu twice daily).

Labour started spontaneously at $35-40$ wk in five of the patients who delivered vaginally. One patient had labour induced at $38 \mathrm{wk}$ since the fetus was deemed to be mature. The patient with PPH underwent induction at $34 \mathrm{wk}$ to facilitate a vaginal delivery (Table III). Elective Caesarean sections were not planned, but we informed all patients about the management of instrumental delivery should the need arise.

\section{Anaesthetic management}

When the patient went into labour, or labour was induced, we stopped heparin therapy and gave protamine in a dose sufficient to reverse the heparin and establish a normal coagulation profile. The patients moved to the delivery room, which was fully equipped for monitoring and operative delivery. Oxygen was administered continuously by mask at $5-6 \mathrm{~L} \cdot \mathrm{min}^{-1}$. Oxygen saturation was monitored continuously using a Hewlett Packard ear oximeter in the early cases and a Nellcor pulse monitor after these became available. A left radial artery catheter and a right internal jugular CVP line were then inserted with local anaesthesia under ECG monitoring. None of the patients had a pulmonary artery catheter (PAC) inserted before delivery, but the CVP introducer allowed such a catheter to be inserted with ease in the postoperative period in the patient with PPH when cardiological intervention became necessary. Before the contractions were too uncomfortable, a lumbar epidural catheter was inserted at the level of the second and third, or third and fourth, intervertebral space. Small incremental doses of local anaesthetic were then injected over $20-45 \mathrm{~min}$ until the patient was comfortable but still aware of the contractions. In the earlier cases, we used bupivacaine $0.375 \%$. With time, as obstetric anaesthesia practice changed, more dilute solutions of bupivacaine $(0.25 \%$ to $0.125 \%$ ) were used and fentanyl $50 \mu \mathrm{g}$.was added. Continuous infusion epidural administration became available after 1986.

All patients laboured in the left lateral position. Antiembolism stockings or elastic bandages were applied to the legs to decrease venous pooling. Outlet forceps, or vacuum extraction, were used to facilitate the delivery and pushing did not occur. In the later cases, no oxytocic medication was given. The anaesthetists were present with the patient throughout labour and delivery. The cardiologist and obstetrician were present at the delivery. Following delivery, the patients returned to the ICU or CCU with an obstetric nurse in attendance. Anticoagulation resumed and monitoring continued. Prophylactic antibiotics (penicillin and gentamicin) were given to all patients. The mothers stayed in the hospital for 2-3 wk.

In contrast, the patient who died had not been seen by the usual team described above. She was transferred from another centre on the day of delivery. A Caesarean section was performed, primarily to save the infant, because of the mother's deteriorating cardiac and respiratory function. The PAC, in this case, was helpful in the anaesthetic and immediate postoperative management and in confirming a diagnosis of pulmonary hypertension.

\section{Discussion}

Pregnant women with PH most often die at the time 
of delivery or in the early post partum period. ${ }^{6}$ At the time of delivery, death may be caused by sudden changes in venous return to the right ventricle with abrupt right ventricular dilatation and failure. This will result in decreased return to the left ventricle with acute left ventricular ischaemia, failure and dysrhythmias. Hypoxia, due to the increased oxygen consumption associated with labour, and the stress of pain, may worsen the clinical picture. In the immediate post-partum period, increased PVR and hypoxia may occur. The mechanism of the increase in PVR is unknown. ' Sudden death post partum has occurred from sinus bradycardia, atrioventricular block and electromechanical dissociation. ${ }^{8}$ In the puerperium death may result from thromboembolic disease. ${ }^{1}$ Minute pulmonary emboli may be fatal in established pulmonary hypertension. The compliance of the pulmonary vasculature is decreased so even a small obstruction may increase right to left shunting and compromise ventricular function.

The management of the pregnant patient with $\mathrm{PH}$ is complex. Ideally the patient should be admitted to hospital before cardiac function deteriorates, usually around $25 \mathrm{wk}$ of pregnancy. Two large reviews of Eisenmenger's syndrome in pregnancy, Gleicher et al.'s paper from 1979 and Stoddart et al.'s literature review of cases published from 1979-1991, stress that complications are best avoided by active prevention starting early in the third trimester. ${ }^{1,3} \mathrm{We}$ admitted our survivors at $25-34 \mathrm{wk}$. One went home for a four-week leave since her condition was stable and she was readmitted at $36 \mathrm{wk}$.

\section{Anticoagulation}

Our patients received anticoagulation therapy for prevention of thromboembolism. Anticoagulation with heparin will prevent venous stasis and clot formation associated with the hypercoagulation of pregnancy and made worse in patients with chronic hypoxia and high haematocrit. Thromboembolic events were a major cause of death in patients reviewed by Gleicher et al. and Stoddart et al. Paradoxical embolism through an intracardiac channel may occur, but a pulmonary embolus with sudden increase in PVR and shunt reversal is more common. Anticoagulation is recommended both ante partum and post delivery. ${ }^{1,9,3}$ We used $s c$ heparin $(5,000-10,000$ iu twice daily). Patients with lower oxygen saturation ( $80 \%$ breathing room air) and chest pain were fully anticoagulated using $i v$ heparin, according to the protocol of the Thromboembolism Service. The heparin dose was adjusted according to the patients' partial thromboplastin time (PTT). When labour started, the heparin effect was reversed using an appropriate dose of protamine to achieve normal coagulation status as judged by PTT and international normalized ratio $<1.2$ (INR). Epidural anal- gesia can be used in patients who receive low-dose $s c$ heparin. ${ }^{10,11}$ We assessed the coagulation status of all our patients before introducing epidural catheters. Our patients were fully informed about the possibility and consequences of epidural haematoma should the coagulation profile remain abnormal. Resuming anticoagulation after delivery is necessary to prevent pulmonary embolism in the puerperium. ${ }^{7}$ Slomka et al. started prophylactic heparin infusion one hour after the epidural catheterization. We did not resume heparin treatment until after the babies were born. None of our patients had serious postpartum bleeding. There is, however, a risk of post-partum haemorrhage when anticoagulation is resumed and death has been reported in some patients. ${ }^{3}$ We think the risk of thromboembolic disease is greater and favour the use of anticoagulants. Heparin was changed to oral Coumadin before discharge from hospital, and therapy continued for several months afterwards.

\section{Oxygen therapy}

The resistance of the pulmonary vasculature may decrease in response to oxygen therapy. Spinnato et al. suggested that fixed pulmonary hypertension, which does not respond to $\mathrm{O}_{2}$, is an indication for early termination of pregnancy since the prognosis is grave. ${ }^{12}$ Oxygen therapy can, therefore, be used as a diagnostic tool and a therapeutic modality. All our patients received $\mathrm{O}_{2}$ by nasal prongs (2-4 $\left.\mathrm{L} \cdot \mathrm{min}^{-1}\right)$ or Ventimask $\left(\mathrm{FIO}_{2} 0.4\right)$ for several hours daily and at night while sleeping. All had some degree of responsiveness to $\mathrm{O}_{2}$ as judged by an increase in $\mathrm{SpO}_{2}$. Pulse oximetry is now readily available, and is an ideal non-invasive monitor which can assess the changes in right-to-left shunting. ${ }^{13}$ We used ear oximetry on all our patients before the pulse oximeter was developed, thus all our patients had non-invasive monitoring on the ward and in labour. Diuresis, which normally occurs after delivery, may increase the haematocrit and thus decrease blood viscosity and compromise pulmonary blood flow. Oxygen therapy should, therefore, continue into the post-partum period until the haematocrit is stable.

\section{Monitoring}

The anaesthestists stayed at the patients' bedside during labour, carefully assessing all changes and taking appropriate action when the need arose. This clinical vigilance is, in our opinion, the best monitor. Careful haemodynamic monitoring is necessary throughout labour and for several days or weeks post-partum. During labour continuous ECG and $\mathrm{SpO}_{2}$ readings are most useful and should be standard. We chose to use intra-arterial blood pressure monitoring in order to facilitate quick decision making. Modern noninvasive blood pressure measuring 
devices may suffice, but an arterial line will provide easy access for serial blood gas samples. Central venous pressure monitoring is recommended. ${ }^{14}$ Insertion of the CVP catheter was the most stressful procedure for our patients because of the Trendelenburg position. Insertion of CVP lines is associated with air emboli, and we were careful to avoid this complication. Infection is an added risk and careful antisepsis was maintained during insertion. We did not find the use of the CVP line altered our management, but this route could have been used for further monitoring, or fluid manipulations, if necessary. The CVP line is helpful in assessing the preload.

We chose not to insert a PAC electively in our patients. The use of a PAC in parturients with Eisenmenger's syndrome remains controversial. The incidence of potentially life-threatening complications is high, and insertion of the catheter may be difficult. Information regarding systemic vascular resistance, right ventricular filling and the degree of shunting can be obtained without a PAC. During parturition, the volume status of the right ventricle can be assessed by the CVP catheter, the systemic blood pressure obtained from the arterial line, and shunting calculated from serial blood gas analyses and $\mathrm{SpO}_{2}$ monitoring. Current texts are explicit in advice regarding the use of PAC during labour: Rocke et al. stated that the high risk of arrythmias, thrombi, paradoxical emboli, pulmonary artery rupture, PDA occlusion and misleading data contraindicate its use. ${ }^{14}$ Mangano advocates monitoring with radial artery and central venous catheters. ${ }^{15}$ Johnson et al. also stressed the need for CVP and arterial lines and pulse oximetry, but argue that PACs may create complications. ${ }^{9}$ The information gained from a pulmonary artery line is limited since the pulmonary resistance is fixed and the PAP is at systemic levels. ${ }^{6}$ Pulmonary catheter wedge pressures are unreliable, and thermodilution cardiac output measurements vary by the degree of shunting through the anatomical defect. Dewitt et al. ${ }^{17}$ reported a patient who died from a presumed embolus when the PAC was withdrawn on the fourth post partum day. The PAP did not help in the patient's management. If a PAC is needed during labour, it should be removed as soon as no further useful information is obtained, preferably after a few hours rather than days. Schwalbe et al. ${ }^{18}$ discussed the difficulty associated with PAC insertion in a parturient with Eisenmenger's syndrome, and ASD, and recommended that the use of a PAC must be decided on a case-by-case basis. Pollack et al. reasoned that the potential complications and spurious information obtained outweighed any benefits in the case described. ${ }^{10}$ Stoddard et $a l^{3}$ did not advocate routine use of PAC in parturients with Eisenmenger's syndrome.

Patients with PPH do not have an anatomical intracardiac shunt. The morphological changes in the pulmo- nary arteries depend on the underlying pathophysiological process, and the reactivity of the vessels vary widely. There are marked swings in vasomotor tone within the pulmonary vascular bed. ${ }^{19}$ Symptoms of the disease, fatigue and dyspnoea, are related to right ventricular dysfunction and low cardiac output. Angina, secondary to right ventricular ischaemia is common. The pulmonary catheter wedge pressure is low or normal. Reactivity of the pulmonary vasculature to vasodilating drugs can be determined with a PAC in place. Roessler $e t$ al. ${ }^{20}$ described testing the response of the pulmonary circulation to fluid challenges, changes in inspired $\mathrm{O}_{2}$ tension and injection of vasoactive substances. Breen et al. ${ }^{4}$ believed that the risks to both mother and fetus from such manoeuvres outweighed the potential benefits. It may be extremely difficult to pass a catheter into the pulmonary artery in these patients because of the low cardiac output, a dilated right ventricle and tricuspid regurgitation. A stiff catheter, especially developed for pulmonary hypertension, may be needed. ${ }^{19}$ Current texts recommend the use of a PAC for delivery. ${ }^{9,14,15}$ Roberts et al. ${ }^{21}$ reviewed the mortality of parturients with PPH before and after the introduction of PAC monitoring. The maternal mortality rate before the use of PAC was 50\%. Since 1982 eight cases monitored with PAC have been reported. $7,8,20,22-26$ Only two patients survived giving a mortality rate of $75 \%$. Roberts et al. concluded that the outcome had not improved in parturients with severe pulmonary hypertension, despite the introduction of invasive cardiovascular monitoring and aggressive circulatory management. ${ }^{21}$ We did not use the PAC during delivery in our one patient with PPH, because we did not think it would greatly alter the management and we were worried about potential complications. The PAC was introduced in the CCU one week post partum and was valuable in monitoring response to therapeutic agents. We think that the use of a PAC for labour and delivery should be assessed on a case-to-case basis in all cases of pulmonary hypertension, with due consideration of benefits and risks.

\section{Analgesia}

The stress of labour is well controlled by epidural analgesia. The oxygen consumption and norepinephrine concentrations are decreased, and the changes in heart rate, blood pressure and cardiac volume associated with contractions of the uterus, and pain of delivery are lessened. The main objection to the use of extradural analgesia in patients with pulmonary hypertension is based on the possibility of precipitating decreases in peripheral vascular resistance and concomitant decreases in blood pressure and venous filling, thereby increasing the right-to-left shunt. There are no reports of severe hypotension because 
of peripheral vasodilatation from high sympathetic block in patients with pulmonary hypertension. ${ }^{27} \mathrm{~A}$ carefully managed epidural, with small increments of local anaesthetic and supervision of blood pressure changes with invasive monitoring, safeguards against a sudden high block. The introduction of continuous epidural infusions, and the addition of small amounts of opioids to the infusate, has made epidural pain relief even safer. There are now several reports on the use of epidural fentanyl and morphine in patients with pulmonary hypertension. ${ }^{10,23,26,27}$ There are no reports that the use of peridural or intrathecal opioids is detrimental, and we found it of value in our patients. Anaesthetic practice changed over the ten year-period described in our paper. In the earlier cases we used more concentrated solutions of bupivacaine, but it has always been our practice to give small aliquots of drug. We did not see any difference in haemodynamic response to the local anaesthetic as we began to use more dilute concentrations. Intravenous narcotics, inhalational analgesics and pudendal blocks have been advocated in patients with pulmonary hypertension because these methods do not reduce systemic vascular resistance or venous return..$^{14,15}$ We do not think that these methods reliably give sufficient analgesia to block the detrimental effects of pain. Carefully conducted epidural analgesia worked very well and was not associated with complications in our cases.

\section{Delivery}

It is important to prevent pushing in patients with pulmonary hypertension. The Valsalva manoeuvre, associated with pushing, may increase right ventricular pressures and the cardiac output normally increases $45 \%$ in the expulsive phase. Our patients were all nursed in the left lateral position with two pillows, to diminish the likelihood of supine hypotensive syndrome. Pooling of blood in the lower extremities was controlled with elastic support stockings. The patients also delivered in a modified Sims position, using a large wedge and elevation of the legs. Haemodynamic variables were stable during parturition in our patient with PPH. Nelson et al. reported that PAP and PVR did not change in a patient who also laboured and delivered in the left lateral position, suggesting that this position may contribute to a relatively stable venous return. ${ }^{8}$

We allowed a $500-1000 \mathrm{ml}$ haemorrhage at the time of delivery to offset the normal autotransfusion from the uteroplacental bed. We did not observe any sudden increase in CVP after the delivery, but several of our patients had a decrease of less than $30 \%$ in systolic blood pressure. We treated the changes in blood pressure with bolus injection of $100-400 \mathrm{ml}$ crystalloid, and did not need the vasopressors and vasodilator drugs prepared for use. Transfusion of blood occurred only in the first case, reflecting changes in clinical practice over the years.

Oxytocic drugs are systemic vasodilators and should be used with caution in patients with $\mathrm{PH}$. Stoddard $e t$ al. ${ }^{3}$ reported a sudden decrease in maternal $\mathrm{SpO}_{2}$ to $75 \%$ following administration of five units synthetic oxytocin in a slow intravenous bolus. Intravenous oxytocin was used for induction in Case \#1 with no untoward effects. Cases \#1-3 were given 50 iu in a slow iv infusion over several hours after birth, as was then the practice. We omitted the use of oxytocin for the other cases, except in Case \#8, where an im dose of five units was given by the obstetrician to increase uterine tone. After the Caesarean delivery, Case \#6 received an infusion of 50 iu oxytocin.

Oxytocin used for induction or augmentation of labour is safe in PH. ${ }^{4}$ Prostaglandin $\mathrm{E}_{2}$, which can cause a decrease in mean systemic arterial pressure and systemic vascular resistance, worked well in one patient, and there were no haemodynamic side effects.

\section{Caesarean section}

When a patient with $\mathrm{PH}$ must undergo a Caesarean section, the prognosis worsens. The mortality is around $70 \%$ in patients with Eisenmenger's syndrome who are delivered by Caesarean section. ${ }^{12}$ Roberts et al. ${ }^{21}$ published the only report of a patient with PPH who survived after Caesarean section. The maternal mortality is increased after Caesarean births in women with normal cardiovascular systems. Women with marginal cardiac reserve and pulmonary hypertension face added risks associated with postoperative fluid shifts, post-surgical pain and a higher incidence of thromboembolism after operative delivery. ${ }^{28}$ The increased mortality after Caesarean section may also be related to the pre-surgical status of the patient, since Caesarean sections are sometimes carried out when the mother is in extremis. ${ }^{21}$ Johnson et al. ${ }^{9}$ advocated elective delivery near term, when fetal lung maturity is reached, to avoid further cardiovascular stresses, and suggested that Caesarean delivery will avoid the stress of labour. The stress of labour, however, can be minimized with good analgesia and careful management. We think it is prudent to avoid elective Caesarean section because of the increased mortality associated with operative delivery in Eisenmenger's syndrome and PPH. Caesarean section may, however, be unavoidable for obstetric reasons, or because the mother's condition is so precarious that she may not survive long enough to deliver vaginally. In such cases, the anaesthetic management is of critical importance for a favourable outcome. There are reports of successful Caesarean delivery with epidural anaesthesia in Eisenmenger's syndrome. ${ }^{12,29}$ If general anaesthesia is chosen, the use of a high-dose narcotic anaesthetic may 
avoid sudden haemodynamic changes associated with induction of anaesthesia and tracheal intubation. ${ }^{30,4}$

\section{Team management}

The team approach to patient management in critical care obstetrics addresses all the complex factors which influence outcome. Good communication and rapport with the patient will decrease anxiety and fear. The patient should know she is critically ill, and that the outcome for her and her baby is questionable. If she understands exactly what is proposed by the management team, and she knows the people who are working with her to optimize outcome, she will be cooperative and an active participant in therapeutic intervention without undue stress. We contend that the multidisciplinary approach to our patients' management contributed considerably to the good outcome in all seven cases in which the team was involved. While the details of medical management changed over the ten years reported here, our patient care, from 1978 onwards, was essentially similar to that advocated by Shime et al. in 1987. They used a multidisciplinary approach, with bed rest, prenatal oxygen, frequent prenatal assessments, and favoured vaginal delivery with well-controlled epidural analgesia. ${ }^{31}$

\section{Conclusion}

We report our management of eight patients with $\mathrm{PH}$ who delivered in our hospital since 1978. Seven patients delivered vaginally and left hospital in good condition and were followed for up to two years post partum. This is the first report from one centre of seven cases of successful outcome following vaginal birth in parturients with PH. All the babies survived. One patient underwent Caesarean section in extremis and died on the day of surgery.

The multidisciplinary team approach to management was associated with a successful outcome in our cases. The obstetrical anaesthetists were integral members of the team and were introduced to the patients early. Our experience suggests that vaginal delivery can be conducted safely in parturients with $\mathrm{PH}$.

\section{Acknowledgements}

We thank Dr. Ernest Fallen MD FRCPC, Department of Medicine, McMaster University, for helpful advice and constructive criticism. We thank Mrs. Valerie Cannon for meticulous attention to detail in typing the manuscript.

\section{References}

1 Gleicher N, Midwall J, Hochberger D, Jaffin $H$. Eisenmenger's syndrome and pregnancy. Obstet Gynecol Surv 1979; 34: 721-41.
2 Jones $A M$, Howitt $G$. Eisenmenger syndrome in pregnancy. BMJ 1965; 1: 1627-31.

3 Stoddart $P$, $O$ 'Sullivan $G$. Eisenmenger's syndrome in pregnancy: a case report and review. International Journal of Obstetric Anesthesia 1993; 2: 159-68.

4 Breen TW, Janzen JA. Pulmonary hypertension and cardiomyopathy: anaesthetic management for Caesarean section. Can J Anaesth 1991; 38: 895-9.

5 Dawkins KD, Burke CM, Billingham ME, Jamieson $S W$. Primary pulmonary hypertension and pregnancy. Chest 1986; 89: 383-8.

6 Gummerus $M$, Laasonen $H$. Eisenmenger complex and pregnancy. Ann Chir Gynaecol 1981; 70: 339-41.

7 Slomka F, Salmeron S, Zetlaoui P, Cohen H, Simonneau $G$, Samii $K$. Primary pulmonary hypertension and pregnancy: anesthetic management for delivery. Anesthesiology 1988; 69: 959-61.

8 Nelson DM, Main E, Crafford $W$, Ahumada GG. Peripartum heart failure due to primary pulmonary hypertension. Obstet Gynecol 1983; 62: 58S-63S.

9 Johnson MD, Saltzman DH. Cardiac disease. In: Datta S (Ed.). Anesthetic and Obstetric Management of High-Risk Pregnancy. St. Louis: Mosby - Year Book, Inc, 1991; 237: 245-51.

10 Pollack KL, Chestnut DH, Wenstrom KD. Anesthetic management of a parturient with Eisenmenger's syndrome. Anesth Analg 1990; 70: 212-5.

11 Wille-Jórgensen P, Jórgensen LN, Rasmussen LS. Lumbar regional anaesthesia and prophylactic anticoagulant therapy. Is the combination safe? Anaesthesia 1991; 46: 623-7.

12 Spinnato JA, Kraynack BJ, Cooper MW. Eisenmenger's syndrome in pregnancy: epidural anesthesia for elective cesarean section. N Engl J Med 1981; 304: 1215-7.

13 Garber $S Z$, Choi HJ, Tremper $K K$, Fujita RA. Use of a pulse oximeter in the anesthetic management of a pregnant patient with Eisenmenger's syndrome. Anesthesiology Review 1988; 15: 59-63.

14 Rocke DA, Rout CC, Orlikowski CEP. Anesthesia and coexisting maternal disease. In: Norris MC (Ed.). Obstetric Anesthesia. Philadelphia: JB Lippincott Company, 1993: 451-4.

15 Mangano DT. Anesthesia for the pregnant cardiac patient. In: Shnider SM, Levinson G (Eds.). Anesthesia for Obstetrics. 3rd ed. Baltimore: Williams \& Wilkins, 1983; 502-8.

16 Robinson $S$. Pulmonary artery catheters in Eisenmenger's syndrome: many risks, few benefits. (Letter). Anesthesiology 1983; 58: 588-9.

17 Devitt JH, Noble WH, Byrick RJ. A Swan-Ganz catheter related complication in a patient with Eisenmenger's syndrome. Anesthesiology 1982; 57: 335-7.

18 Schwalbe SS, Deshmukh SM, Marx GF. Use of pulmonary artery catheterization in parturients with Eisen- 
menger's syndrome. (Letter). Anesth Analg 1990; 71:

442-3.

19 Rich S. Primary pulmonary hypertension. Prog Cardiovasc Dis 1988; 31: 205-38.

20 Roessler P, Lambert TF. Anaesthesia for Caesarean section in the presence of primary pulmonary hypertension. Anaesth Intensive Care 1986; 14: 317-20.

21 Roberts NV, Keast PJ. Pulmonary hypertension and pregnancy - a lethal combination. Anaesth Intensive Care 1990; 18: 366-74.

22 Sørensen $M B$, Korshin JD, Fernandes $A$, Secher $O$. The use of epidural analgesia for delivery in a patient with pulmonary hypertension. Acta Anaesthesiol Scand 1982; 26: 180-2.

23 Robinson DE, Leight CH. Epidural analgesia with lowdose bupivacaine and fentanyl for labor and delivery in a parturient with severe pulmonary hypertension. Anesthesiology 1988; 68: 285-8.

24 Feijen HWH, Hein PR, van Lakwijk-Vondrovicova EL, Nijhuis $G M M$. Primary pulmonary hypertension and pregnancy. Eur J Obstet Gynecol Reprod Biol 1983; 15: 159-64.

25 Takeuchi T, Nishii O, Okamura T, Yaginuma T. Primary pulmonary hypertension in pregnancy. Int $\mathbf{J}$ Gynecol Obstet 1988; 26: 145-50.

26 Abboud TK, Raya J, Noueihed R, Daniel J. Intrathecal morphine for relief of labor pain in a parturient with severe pulmonary hypertension. Anesthesiology 1983; 59: 477-9.

27 Power KJ, Avery AF. Extradural analgesia in the intrapartum management of a patient with pulmonary hypertension. Br J Anaesth 1989; 63: 116-20.

28 Gilman $D H$. Caesarean section in undiagnosed Eisenmenger's syndrome. Anaesthesia 1991; 46: 371-3.

29 Atanassoff P, Alon E, Schmid ER, Pasch Th. Epidural anesthesia for cesarean section in a patient with severe pulmonary hypertension. Acta Anaesthesiol Scand 1989; 33: 75-7.

30 Batson $M A$, Longmire $S$, Csontos $E$. Alfentanil for urgent Caesarean section in a patient with severe mitral stenosis and pulmonary hypertension. Can J Anaesth 1990; 37: 685-8.

31 Shime J, Mocarski EJM, Hastings D, Webb GD, McLaughlin PR. Congenital heart disease in pregnancy: short- and long-term implications. Am J Obstet Gynecol 1987; 156: 313-22. 